\title{
Paleomagnetic behavior of volcanic rocks from Isla Socorro, Mexico
}

\author{
Elise Sbarbori ${ }^{1}$, Lisa Tauxe ${ }^{1}$, Avto Goguitchaichvili ${ }^{2}$, Jaime Urrutia-Fucugauchi ${ }^{3}$, and Wendy A. Bohrson ${ }^{4}$ \\ ${ }^{1}$ Scripps Institution of Oceanography, La Jolla, CA 92093-0220 \\ ${ }^{2}$ LIMNA, Instituto de Geofisica, Universidad Nacional Autonoma de Mexico, Campus Morelia, Michoacan, Mexico \\ ${ }^{3}$ Laboratorio de Paleomagnetismo y Paleoambientes, Instituto de Geofisica, Universidad Nacional Autonoma de Mexico, \\ Mexico City 04510 DF, Mexico \\ ${ }^{4}$ Department of Geological Sciences, Central Washington University Ellensburg, WA 98926-7418
}

(Received November 1, 2007; Revised February 25, 2008; Accepted March 3, 2008; Online published January 23, 2009)

\begin{abstract}
The direction and magnitude of the geomagnetic field vary both spatially and temporally and undergo significant departures from that of a geocentric axial dipole. In order to properly characterize persistent behaviors, time-averaged field models must be based on the highest quality data. Here we present full-vector paleomagnetic data for volcanic units exposed in the southeast quadrant of the island of Socorro, Mexico. We carried out a joint expedition between the Scripps Institution of Oceanography and the Universidad Nacional Autónoma México to Isla Socorro in January of 2005 during which we collected oriented paleomagnetic samples from 21 sites, representing as many as 10 different volcanic units (the oldest of which is $\sim 540 \mathrm{ka}$ ). We subjected over 100 specimens to the most up-to-date paleointensity methods, and included the standard reliability checks. In an earlier study, Bohrson et al. (1996) proposed a series of widespread eruptive events, based on similarities of argon/argon dates. Paleointensity from specimens that conform to the strictest acceptance criteria are available from both the (unoriented) original sample collection and our fully oriented (but as yet undated) new collection. Correlation between the two collections is however problematic. The time-averaged direction from Socorro is consistent with that expected from a geocentric axial dipole, and the time-averaged intensity is $30.0 \pm 7.1 \mu \mathrm{T}$, equivalent to a virtual axial dipole moment (VADM) of 67.6 $\pm 16.0 \mathrm{ZAm}^{2}$.
\end{abstract}

Key words: Paleomagnetism, paleointensity, Socorro, Bruhnes, IZZI method.

\section{Introduction}

The geomagnetic field is generated by the fluid motion of liquid iron in the Earth's outer core. Earth's magnetic field is a vector quantity, meaning that at any point in space it is described by both a direction and a magnitude. To first order, the geomagnetic field is approximated by the field produced by a bar magnet aligned with the spin axis. This approximation is known as the geocentric axial dipole (GAD) hypothesis, and is the fundamental field model used in paleomagnetism.

Despite overall simplicity, the geomagnetic field is not static. Its direction and magnitude vary both spatially and temporally and undergo significant departures from GAD. Existing models of the time-averaged field (TAF) contain long-term deviations from GAD. In order to characterize these deviations better, a more thorough spatial and temporal coverage of high-quality full vector paleomagnetic data is required (Johnson et al., 2003).

Most paleomagnetic studies have focussed solely on directional data, as absolute paleointensities are much more difficult to determine. Existing observations indicate a connection between direction and intensity (i.e. during field reversals or excursions the field strength as recorded in the rocks is observed to be low), yet such full vector data re-

Copyright (c) The Society of Geomagnetism and Earth, Planetary and Space Sciences (SGEPSS); The Seismological Society of Japan; The Volcanological Society of Japan; The Geodetic Society of Japan; The Japanese Society for Planetary Sciences; TERRAPUB. main sparse. Paleointensity information is particularly important in field models because it could have implications for geodynamo modeling, interactions at the core-mantle boundary, and the formation and growth of the inner core.

Isla Socorro, at roughly $20^{\circ} \mathrm{N}$, shares approximately the same latitude as the island of Hawaii and the trans-Mexican volcanic belt. Many paleomagnetic data in global data compilations (e.g., Jonson and McFadden, 2007) are biased because of the concentrated interest in (and oversampling of) the Hawaiian islands. Thus, geomagnetic field features which may be particular to that area, for example the purported presence of a "Pacific dipole window", characterized by low directional scatter (Doell and Cox, 1972) or the large negative inclination anomalies (Laj et al., 1999) may be over-represented in the data that go into time-averaged field models. Furthermore, because of the difficulty of finding suitable materials for absolute paleointensity studies there is a dearth of high-quality intensity information available, hence even limited full vector data points from Isla Socorro can contribute to a better understanding of paleosecular variation and the time-averaged field.

In this study, our aim was to contribute to the global paleomagnetic database by obtaining directional and intensity data and by matching those data to well-constrained ages. In addition, we compare what we observe at Isla Socorro to other sites at $\sim \pm 20^{\circ}$ latitude. We then consider implications for the geologic history of Isla Socorro. Finally, we discuss whether silicic volcanics (in particular, silicic per- 

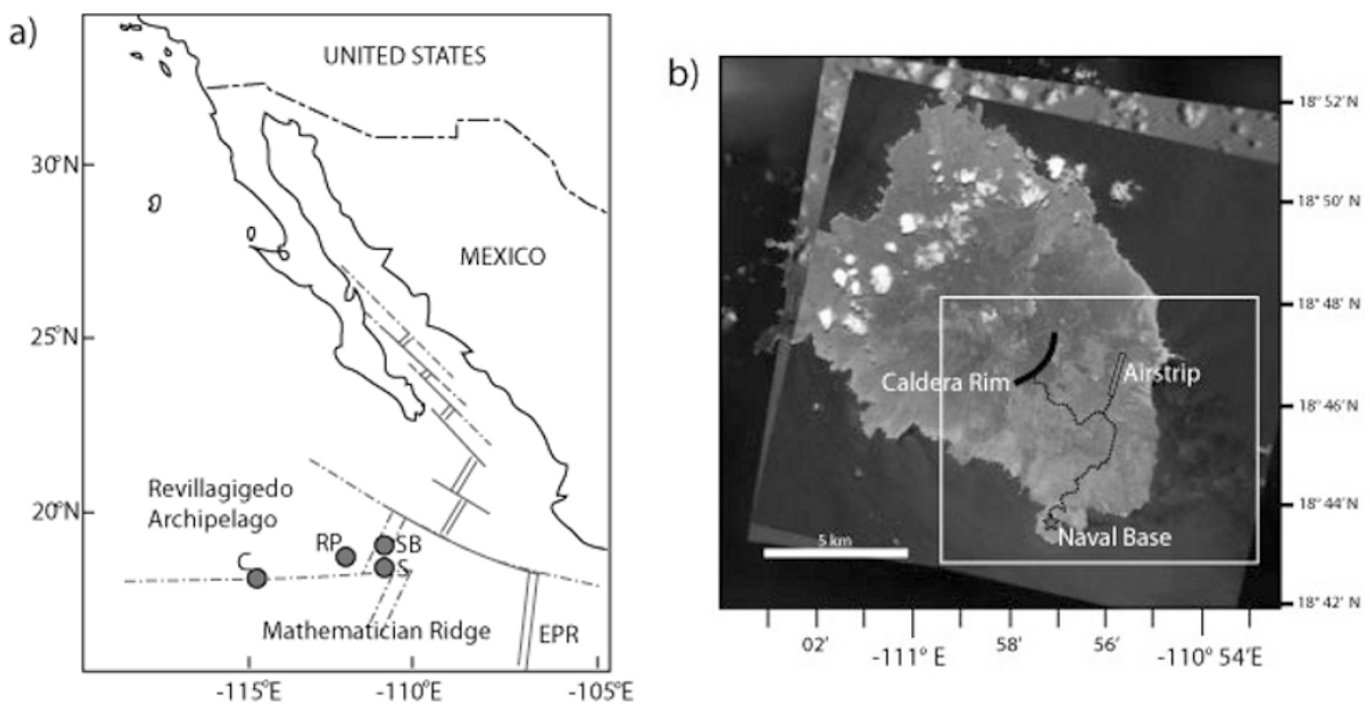

Fig. 1. Map of Mexico and the Revillagigedo Archipelago: (a) The Revillagigedo Archipelago sits on the Mathematician Ridge (map redrawn after Farmer et al., 1993). Red dots indicate the four islands. S: Socorro, SB: San Benedicto, RP: Roca Partida, C: Clarion. The East Pacific Rise (EPR) sits to the east. (b) A closeup of Isla Socorro showing the naval base, airstrip and caldera rim. The dashed lines are dirt roads. Rocks are best exposed in the southeast quadrant of the island (the area of focus in this study). Map courtesy of Google Earth.

alkaline ignimbrites) can be suitable materials for further paleointensity studies.

\section{Geological Background}

\subsection{Mathematician Ridge and the Revillagigedo Archipelago}

The Revillagigedo Archipelago (Fig. 1) comprises four islands: Socorro, San Benedicto, Clarion and Roca Partida. The archipelago is adjacent to the northern end of the Mathematician Ridge, a fossil ridge crest that ceased spreading circa $3.5 \mathrm{Ma}$ when activity shifted approximately $500 \mathrm{~km}$ eastward to the present-day East Pacific Rise (Mammerickx et al., 1988). Although most Pacific spreading centers have distinct morphological features that are characteristic of faster spreading rates including smooth topography and broad axial highs, the Mathematician Ridge has many morphological similarities to the slower-spreading Mid-Atlantic Ridge, including a more jagged topography, and an axial rift valley. These features are most likely the result of spreading rates gradually slowing to a halt before and during the plate boundary reorganization event (Mammerickx et al., 1988; Batiza and Vanko, 1985).

The Revillagigedo Archipelago is unique because it is the only ridge-associated set of islands in the Pacific Ocean to display silicic-peralkaline volcanism, although petrologically similar islands are found in the Atlantic Ocean (e.g., the Azores (White et al., 1979)). Silicic-peralkaline volcanism is typically associated with slow spreading rates which produce smaller amounts of melt that have higher silica content than faster spreading environments. Therefore silicic-peralkaline rocks are found in the Atlantic (where rates average $5 \mathrm{~cm} / \mathrm{yr}$ ) but not usually in the Pacific (where faster rates produce higher volumes of melt which are less differentiated, hence have lower silica content). As the Mathematician Ridge slowed to a halt, the melt underwent fractional crystallization, resulting in even rhyolitic flows (Bohrson et al., 1996). However, residual melt from sea floor spreading is difficult to account for the relatively large amount of melt produced in the archipelago which is more consistent with a mantle plume source (Bohrson et al., 1996).

\subsection{Isla Socorro}

Isla Socorro is the largest of the four islands in the Revillagigedo Archipelago. The island, a basaltic shield volcano, sits on the Pacific plate at the northern end of the Mathematician Ridge, about $700 \mathrm{~km}$ due west of Manzanillo on mainland Mexico. The majority of the rocks exposed subaerially are silicic-peralkaline in composition (Bohrson and Reid, 1997). The main volcanic edifice, Cerro Evermann, rises $\sim 1400$ meters above sea level. Other volcanic features on its flanks include domes, cones, lava flows, and possible ignimbrite deposits (Bryan, 1960; Bohrson et al., 1996). Most of the island is heavily vegetated, but the southeast corner is more sparsely vegetated and is marked by deep ephemeral stream channels where exposure is excellent. The island is uninhabited except for a small Mexican naval base at the southernmost tip. While there is an airstrip and several roads, most of the field work was done on foot (Fig. 1(b)).

2.2.1 Eruptive history and age constraints At the summit of Cerro Evermann there is a large 60 meter escarpment that is likely the remains of a collapsed summit caldera (dark bar in Fig. 1(b)). Bohrson et al. (1996), using argonargon geochronology, geologic mapping, and stratigraphic relations, divided the history of subaerial volcanism (and the resulting geologic units) into three distinct groups based on the timing of caldera formation: precaldera, syncaldera and postcaldera formations.

Pre- and syn-caldera formations are dated from 550 to $350 \mathrm{ka}$. Within this window, the 21 ages cluster together in several distinct eruptive periods, which Bohrson et al. (1996) interpret as eruptive periodicity, with periods of inactivity lasting about $30 \mathrm{kyr}$. The eruptive periods are divided into age groups "A" (oldest) through "E" as in Fig. 2. 


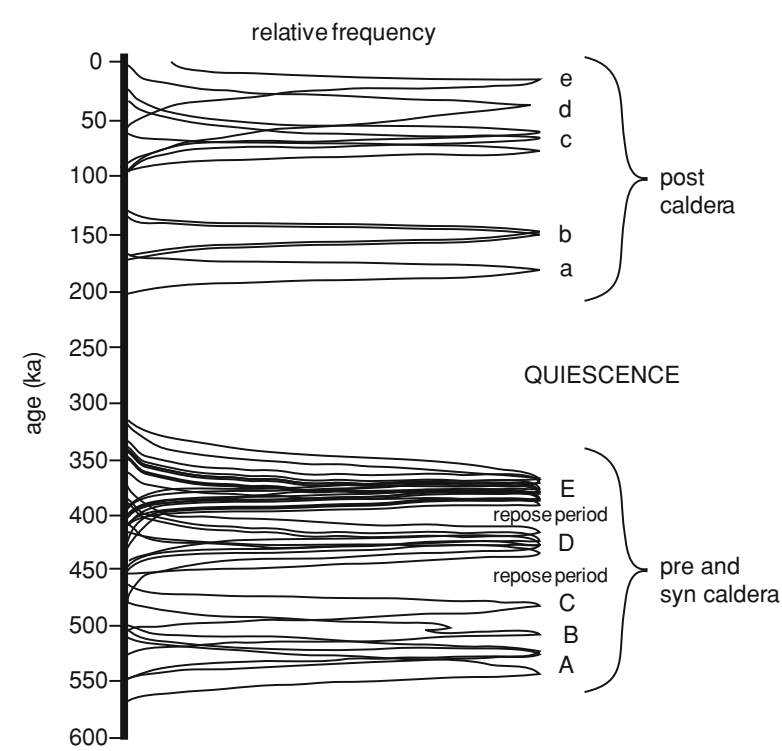

Fig. 2. Argon-argon ages and interpretations: Each spike represents the probable age of rocks from each site from Bohrson et al. (1996), as determined by the Ar-Ar dating method (figure redrawn from that study). Probability density functions are defined by analysis of 6-12 alkali feldspar separates per sample.

Post-caldera formations, which include the Cerro Evermann formation (trachytes and rhyolites) and the Lomas Coloradas formation (alkalic basalts and trachyte domes), erupted contemporaneously and represent a period of volcanic activity dating from $180 \mathrm{ka}$ to at least $15 \mathrm{ka}$. There are no dated units between the deposition of the pre- and synand the post-caldera volcanics which Bohrson et al. (1996) interpret as a $200 \mathrm{kyr}$ period of quiescence. While they do not suggest an eruptive periodicity in the post-caldera rocks (and neither do we), we label the five post-caldera age groups "a" (oldest) through "e", for our convenience (Fig. 2).

Other attempts at constraining age relationships on Socorro include the radiocarbon dating of lacustrine sediments (Farmer et al., 1993). However, previous attempts of using the potassium-argon and argon-argon methods for age dating of the volcanics (particularly of the basalts) proved difficult, due in large part to the fact that the island is relatively young (Farmer et al., 1993) and virtually inaccessible, without the aid of the Mexican Navy.

The pre- and syn-caldera rocks are of particular interest to this study because they were interpreted as ignimbrites by Bohrson et al. (1996), and the documented presence of iron oxides in the single domain (SD) size range in welded tuffs (Schlinger et al., 1991) raised the possibility that they may be suitable for paleointensity studies. Secondly, the high glass content in these silica-rich rocks may "protect" the minerals from alteration during the laboratory heating experiments (in the same manner as submarine basaltic glass (Selkin and Tauxe, 2000)). Moreover, and more importantly, a preliminary paleomagnetic study performed at the Scripps Institution of Oceanography on unoriented samples from this area showed promising results which suggested that these pre- and syn-caldera deposits might be of use as a suitable material for paleointensity studies (see Section 3).

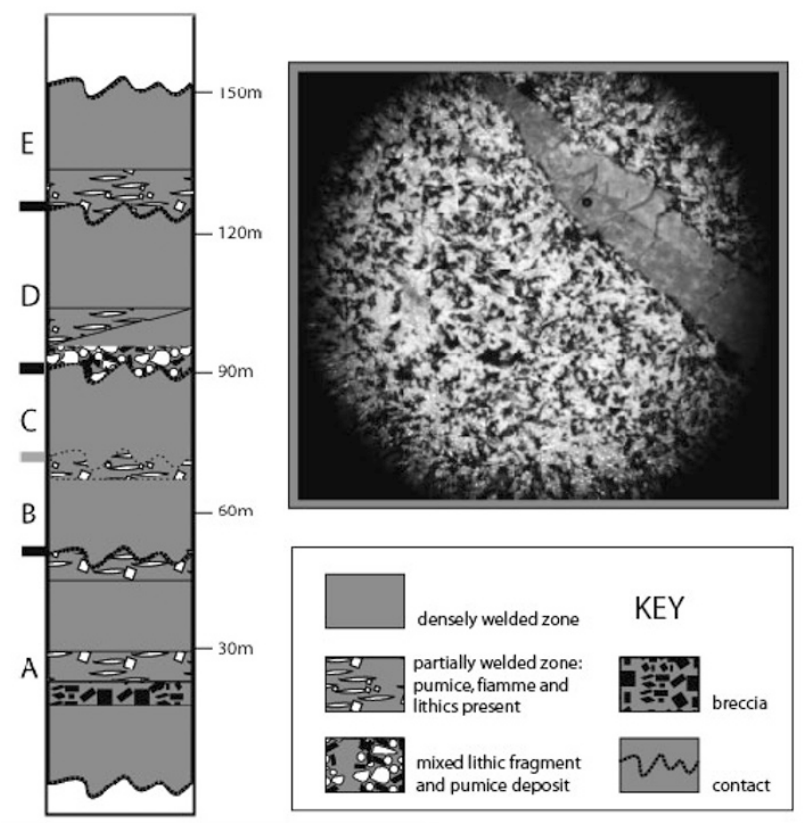

Fig. 3. Stratigraphic column of pre- and syn-caldera volcanics and representative photomicrograph. Sequence of volcanics, redrawn from Bohrson et al. (1996), showing age group, welding zonation and unit thicknesses. Densely welded zones reportedly increase in degree of welding upsection. A typical photomicrograph from specimens collected this study shows no evidence of welding.

Subaerial exposure of pre- and syn-caldera rocks is dominated by peralkaline rhyolites and trachytes. Exposure of precaldera basalt is limited to the base of an inaccessible cliff on the eastern side of the island (Bohrson et al., 1996; Bryan, 1960). The silicic rocks are porphyritic, with alkalic feldspar as the dominant phenocryst phase. Drainage cuts on the eastern side of the island provide workable exposure of pre- and syn-caldera silicic units. The dominant lithofacies for pre- and syn-caldera silicic units is massive and lacks lithic fragments. The base of most units is poorly exposed. In rare cases, a partially welded zone $(<5 \mathrm{~m}$ thick) with fiamme structures and lithic fragments were observed (Bohrson et al., 1996). Where well preserved, flows overlie pyroclastic material. Most units preserve a zone of abundant lithic fragments at the base (see redrawing of their stratigraphic column, Fig. 3). Based on these observations, Bohrson et al. (1996) suggested that the pre- and syn-caldera units are dominantly explosive in origin (i.e., ignimbrites). The flows increase in hardness and preservation upward from the base grading into non-vesiculated, dense zones that lack lithic fragments (see redrawing of their stratigraphic column, Fig. 3). Also interspersed in some units are breccias and extremely poorly sorted ash flows (with large chunks of pumice up to $50 \mathrm{~cm}$ ). It is of note that what Bohrson et al. (1996) call the "thick welded zone" is the major rock type exposed. In our investigations, we found no evidence of welding. We targeted the densest material that was freshly exposed in the stream beds for sampling.

2.2.2 Present-day eruptive activity Volcanic activity in the area continues to the present. Flank eruptions on Socorro were observed in 1848 and again in 1951 (Richards 
and Brattstrom, 1959). Volcán Bárcena, on the nearby island of San Benedicto, erupted in 1952 (Richards, 1966). While no one has observed an eruption from the main volcanic edifice on Socorro, hydrothermal activity at the summit caldera, including steam vents, mud pools and hot springs are still observed (Taran et al., 2002). The most recent activity in the region occurred in 1993, when a submarine eruption occurred to the west of Socorro, ejecting floating blocks of basaltic scoria and reticulite (Siebe et al., 1995).

\section{Methods}

\subsection{Field methods}

We collected paleomagnetic samples from 20 sites on the southeastern quadrant of Socorro Island, selecting outcrops that were unaltered and in situ (black dots in Fig. 4). Sampling targets included sites that were previously argonargon dated by Bohrson et al. (1996) (red squares in Fig. 4). Most of these units are exposed in ephemeral drainage cuts on the east coast of the island.

Because the original study predated the widespread use of global positioning systems (GPS) finding the original sampling locations was difficult. We attempted to relocate the original sample sites using a topographic map, the original field notes, and a GPS. While in some cases we were confident that we sampled the correct cooling units, other times we were less certain.

In total, we collected samples from 16 sites mapped as the ignimbritic pre- and syn-caldera formation, 3 sites from the Cerro Evermann formation and 1 site from a trachytic Lomas Coloradas flow. We avoided sampling any horizons containing lithics, as lithic fragments may have a larger range of magnetic grain size and were thought to be less de-

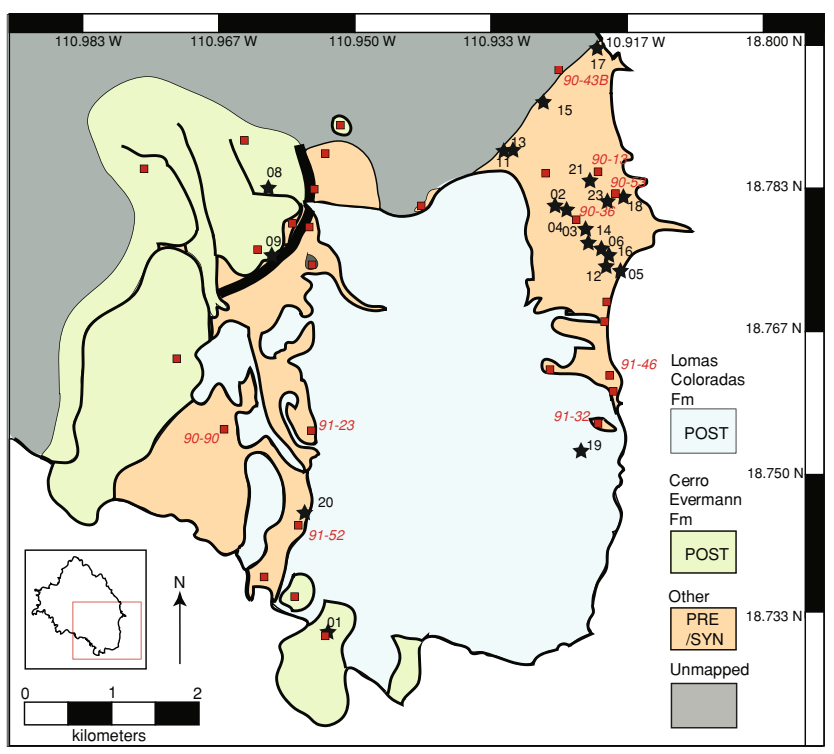

Fig. 4. Geologic map of the southeastern quadrant of Isla Socorro showing lithologic units and site locations: Red squares are sites collected by Bohrson et al. (1996). Labeled squares indicate samples that have undergone paleointensity tests at the Scripps Institution of Oceanography prior to this study. Black dots are sites collected during this study. Results for all paleointensity experiments are available in the MagIC database at http://earthref.org. Map redrawn from Bohrson et al. (1996). sirable than the fine grained matrix. We also preferentially selected the hardest and freshest material (represented by the solid color in Fig. 3). For any given site, we spread our sampling effort across the outcrop, used different drill angles and sampled different blocks within each cooling unit to recognize post-cooling rotations and also minimize the effect of orientation error. A minimum of 10 cores were drilled at each site, with most cores at least three inches in length. We oriented the cores using a Pomeroy orientation device, and where possible, we measured declination using both a magnetic and sun compass. No bias of the magnetic compass directions was observed.

\subsection{IZZI experiment}

We sliced all samples into one-inch paleomagnetic specimens and made a thin section from representative material from each site. All magnetic measurements were made at the Scripps Institution of Oceanography Paleomagnetics Laboratory.

NRM directions were measured for all specimens on a CTF cryogenic magnetometer. Two sites, sc01 and sc18 had scattered NRM directions, apparently the result of lightning strikes, and were discarded for further paleointensity experiments. Stepwise alternating field (AF) demagnetizations were carried out for at least one specimen per site (in the Sapphire Instruments SI-4 uniaxial AF demagnetizer) to obtain their characteristic remanent magetization (ChRM).

We subjected 90 specimens to an IZZI paleointensity experiment (e.g., Tauxe et al., 2004), in which the Aitken (Aitken et al., 1988) and Coe (Coe, 1967) variants of the Thellier-Thellier experiment are alternated. In general, we use a custom built oven with heating and cooling done "in place". Specimens are placed in a holder with at least $1 \mathrm{~cm}$ spacing between them and always placed in exactly the same location for repeated steps in order to avoid contamination of specimens with the magnetization from neighboring specimens and to maximize temperature reproducibility.

After heating to temperature $T_{1}$, cooling in zero field and measuring the specimen magnetization, the specimens were reheated to $T_{1}$ and cooled in a $25 \mu \mathrm{T}$ laboratory field applied along the length of the cylindrical specimens $(-Z$ direction in specimen coordinates), completing the first zero-field/infield (ZI) step. Next, we heat the specimens to $T_{2}>T_{1}$ and cool them in the same laboratory field. After measuring the specimen magnetization, the specimens are reheated to $T_{2}$ and cooled in zero field. This completes the first set of "IZ" steps.

This protocol is repeated throughout the experiment, with alternating sets of "ZI" and "IZ" heating steps. In addition to these steps, we also include the standard pTRM checks in which the sample is reheated to a previous temperature step in the laboratory field and its ability to acquire a remanence is compared to the previous step. Even though the IZZI method is sensitive to high temperature tails, we built in pTRM tail checks after the "ZI" steps, whereby a zero field step is repeated in order to check that all the pTRM acquired in the in-field step is erased at the same temperatuare (e.g., Riisager and Riisager, 2001).

Selkin et al. (2007) suggested that the linearity assumption for Thellier-type experiments is not always valid, even at low very low fields (on the order of tens of $\mu \mathrm{T}$ ). In or- 


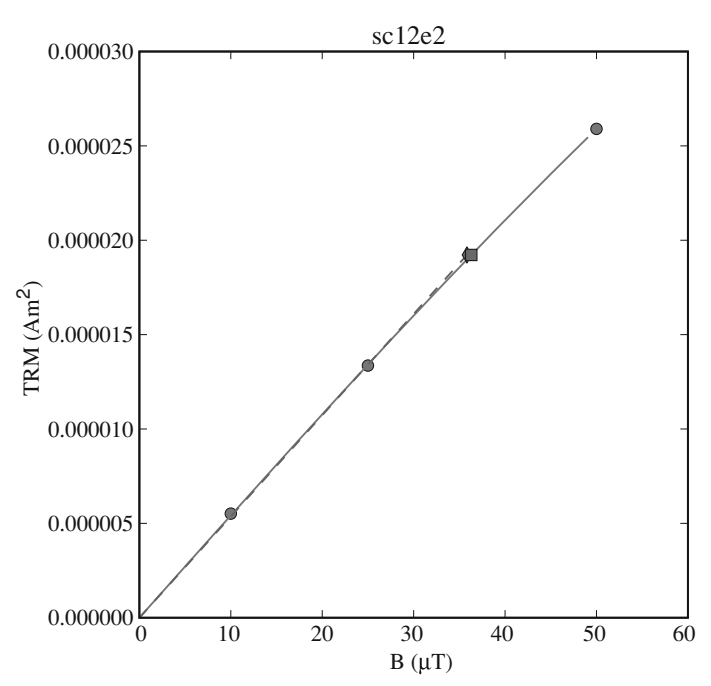

Fig. 5. Typical results from the TRM acquisition experiment: Green circles represent the TRM acquired in 10, 25 and $50 \mu \mathrm{T}$ laboratory fields at $600^{\circ} \mathrm{C}$. Blue diamond represents $B_{\text {anc }}$ obtained assuming linearity. Red square represents $B_{\text {anc }}$ calculated using the best fit hyperbolic tangent function through the TRM acquisition experiment. The blue diamond falls on top of the red square, demonstrating that the linearity assumption is appropriate.

der to test the validity of the linearity assumption, we subjected selected specimens (those that had showed no alteration based on pTRM checks in the IZZI experiment) to a TRM acquisition experiment. Specimens were given a total TRM in 10, 25 and $50 \mu \mathrm{T}$ laboratory fields, cooling from $600^{\circ} \mathrm{C}$. We plot the TRM acquired versus the laboratory field in Fig. 5. We fit the TRM acquisition data using the best fit hyperbolic tangent function and compare our estimated $B_{\text {anc }}$ (assuming linearity) to a $B_{\text {anc }}$ calculated using the best fit hyperbolic tangent function through the TRM acquisition data. In most cases, the two values are the same or very similar, demonstrating that the linearity assumption is appropriate for this experiment, and that no corrections are necessary.

\section{Results}

\subsection{Good data}

In a Thellier-type experiment, the ideal specimen has a linear, single-component Arai plot that passes all pTRM checks. In addition, the magnetization remaining after the zero field steps demonstrates that the NRM is a single vector (e.g. should decay linearly toward the origin in the $\mathrm{Zi}$ jderveld diagram). Two examples of "successful" experiments are shown in Fig. 6.

The top row of graphs in Fig. 6(a)-(c) shows the thermal demagnetization and remagnetization curves, the $\mathrm{Zi}$ jderveld diagram and the Arai plot for a representative specimen from this study (sc12e2). The bottom row of graphs, Fig. 6(e)-(f), show the same, but for a specimen from a preliminary study (specimen 90-43Ba2) which employed the Coe-modified Thellier experiment (ZI only) on samples collected by Bohrson et al. (1996). In both cases, the Zijderveld diagram decays in a straight line toward the origin. The low temperature portion that does not point toward the origin (a possible viscous overprint) is not included in our slope estimation. The Arai diagrams, shown in Fig. 6(c) and Fig. 6(f), are linear, have reproducible pTRM checks (triangles) and the pTRM tail checks (squares) suggest complete removal of pTRMs gained at a particular in-field cooling step by reheating and cooling in zero field.

\subsection{Typical magnetic behaviors}

As in many paleointensity studies, we observe non-ideal behavior in many specimens. We categorize these behaviors into four groups based on the morphology of the thermal demagnetization, Zijderveld and Arai plots.

\section{I: "Humped" demagnetization curve (Fig. 7)}

Specimens with a marked decrease in magnetization between the $200^{\circ} \mathrm{C}$ degree and the $400^{\circ} \mathrm{C}$ degree temperature steps have a humped thermal demagnetization curve.

\section{II: Curved Arai plot (Fig. 8)}

Specimens exhibit several characteristic behaviors, the most obvious of which is a two slope or concave up curve in the Arai plot (when pTRM gained is plotted against the remaining NRM, the resulting curve is concave-up). In addition, the Zijderveld diagrams display two components and the high temperature steps may 'zig-zag' toward the origin, with the IZ steps closer to the lab field $(-Z$ direction, specimen coordinates) and the ZI steps further away (i.e. also display mild III behavior). These specimens typically pass pTRM checks even up to high temperatures.

\section{III: Arched zig-zagging of the Zijderveld diagram (Fig. 9)}

These poorly-behaved specimens acquire a magnetization parallel to the lab field in the IZ steps which is only partially removed in the zero field part. In the subsequent IZ step, this lab field component is reduced, creating the arched and zig-zaging shape of the Zijderveld diagrams. These specimens typically pass their pTRM checks, but frequently fail their pTRM tail checks.

\section{IV: Sharp pTRM gain/loss behavior (Fig. 10)}

Some specimens display a sudden increase in partial thermoremanent magnetization in a single in-field temperature step that then disappears in subsequent steps. This behavior yields a large spike in both the Arai plot and the thermal demagnetization (remagnetization) curve. (The specimen shown in Fig. 10 also displays Type III behavior in the $\mathrm{Zi}$ jderveld diagram.)

There are several possible causes for the "spike" in pTRM acquisition, for example, incorrect intensity applied during the in-field step, sudden growth of a new magnetic mineral at a given heating step which is destroyed in the subsequent heating step, or self-reversal. We are able to rule out the possibility that an incorrect laboratory field was used at that temperature step because this behavior affected only two specimens of the 30 that were involved in each of two heating batches of the three boats of the SC series. Neighboring specimens were unaffected and it seems to have afflicted specimens from the same sites (but treated in different batches). Sudden growth and rapid demise of a magnetic phase also has some difficulties in that in all cases where the "spike" is observed, it is associated with a 

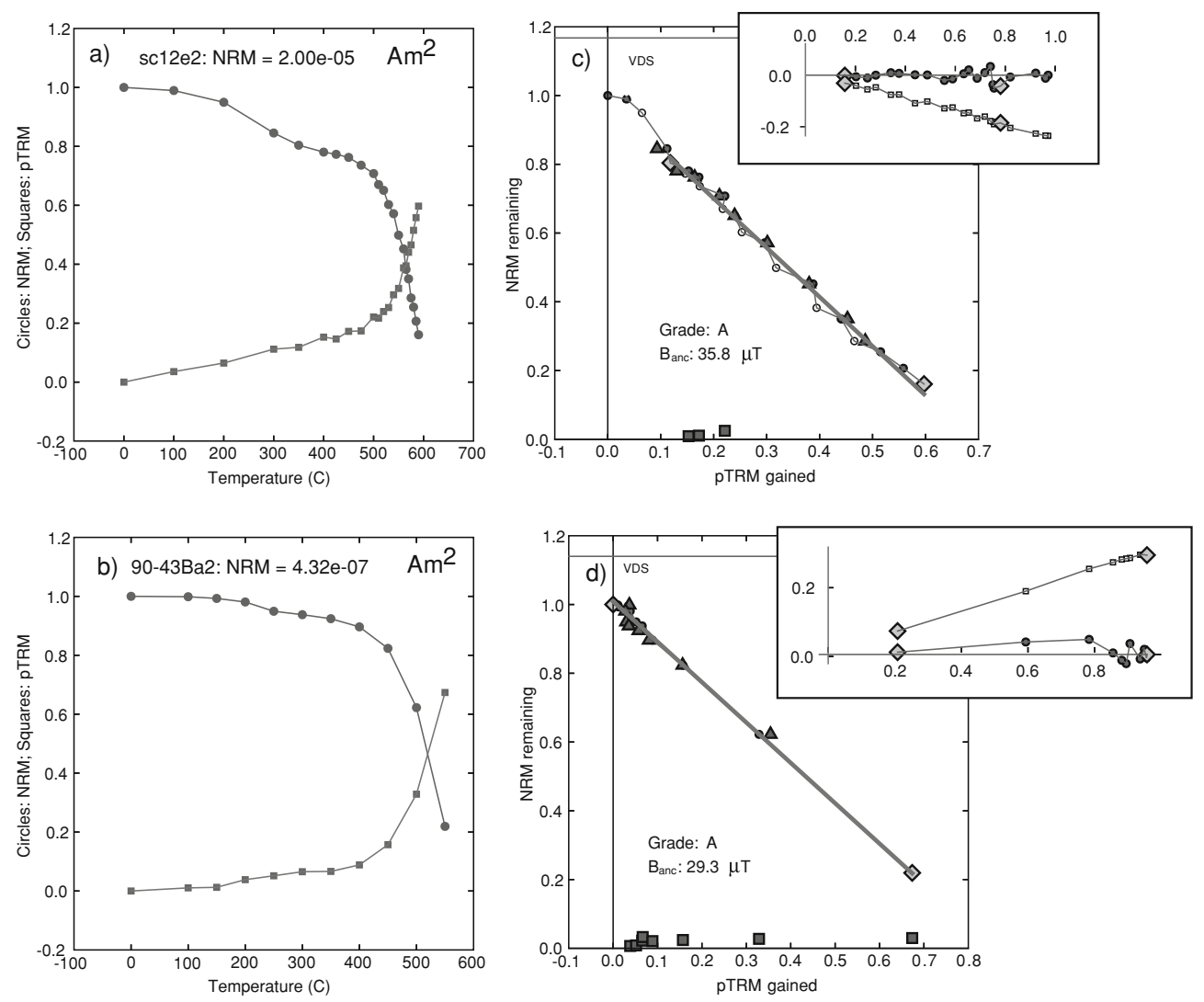

Fig. 6. Representative near-ideal specimen behavior: (a)-(b) thermal demagnetization (dots) and remagnetization (squares) curves. (c)-(d) Arai plots, in which NRM remaining is plotted against pTRM gained. Solid circles are zero-field first, in-field (ZI) steps. Open circles are in-field first, zero-field (IZ) steps. Blue triangles are pTRM checks, blue squares are pTRM tail checks. The green line is the line of best fit between two (handpicked) temperature steps (yellow diamonds), and the slope of this line is used in calculating $B_{\text {anc }}$. The blue line is the vector difference sum. Insets to (c)-(d) Zijderveld diagram (specimen coordinates). Solid circles represent the horizontal plane, open squares represent the vertical plane. The $x$-axis is rotated to align with the specimen NRM direction.
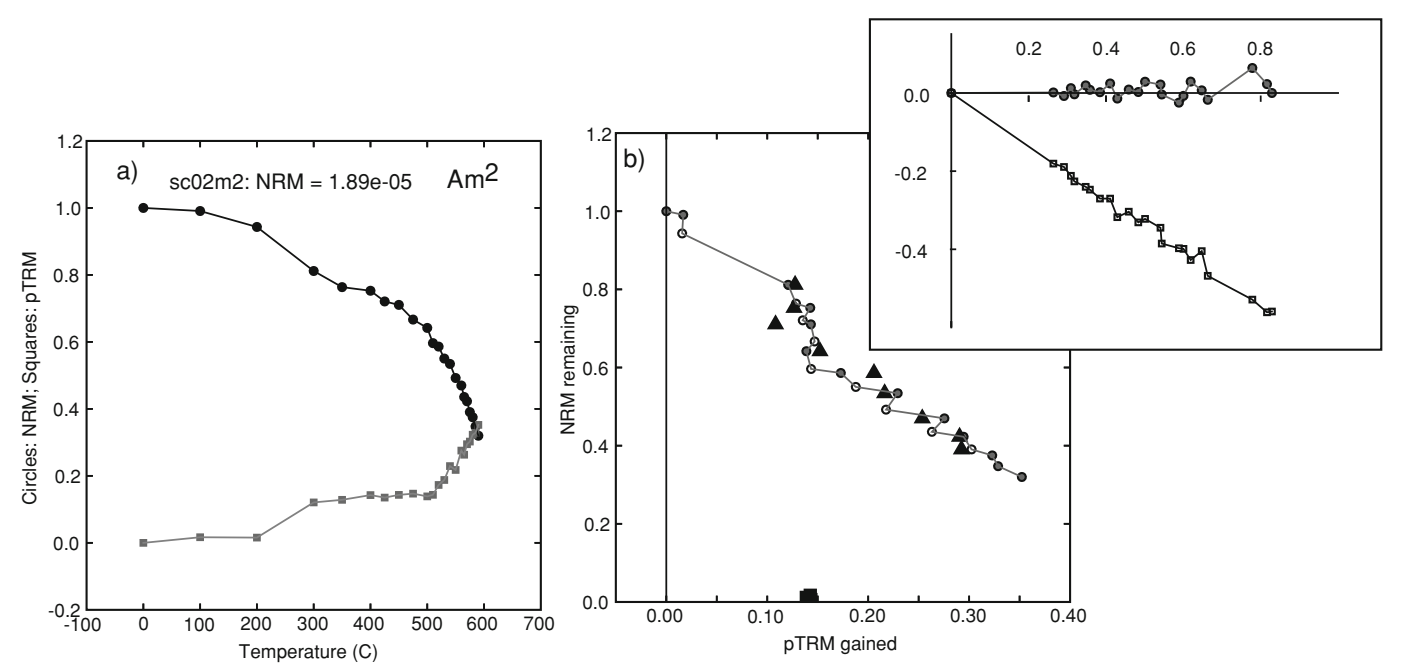

Fig. 7. Representative non-ideal specimen behavior: I. A typical demagnetization-remagnetization plot (a), Arai plot (b), and inset to (b) Zijderveld diagram. Type I specimens are not rejected a priori. However for paleointensity determinations, only the corresponding portion of the Arai plot that excludes the first hump in the demag/remag plot is used.

large deflection of the pTRM acquired in the in-field step, not toward the lab field, but AWAY from the lab field. This observation would support some sort of self-reversal behavior. What remains puzzling is that the behavior disappears at higher temperature steps.

It is worth mentioning that some of our otherwise "well- behaved" specimens exhibit IV behavior including, for instance, our example of a near-ideal specimen in Fig. 6. We have not excluded them from acceptance a priori; we simply take this behavior into consideration during our interpretation (see Section 4.4). 

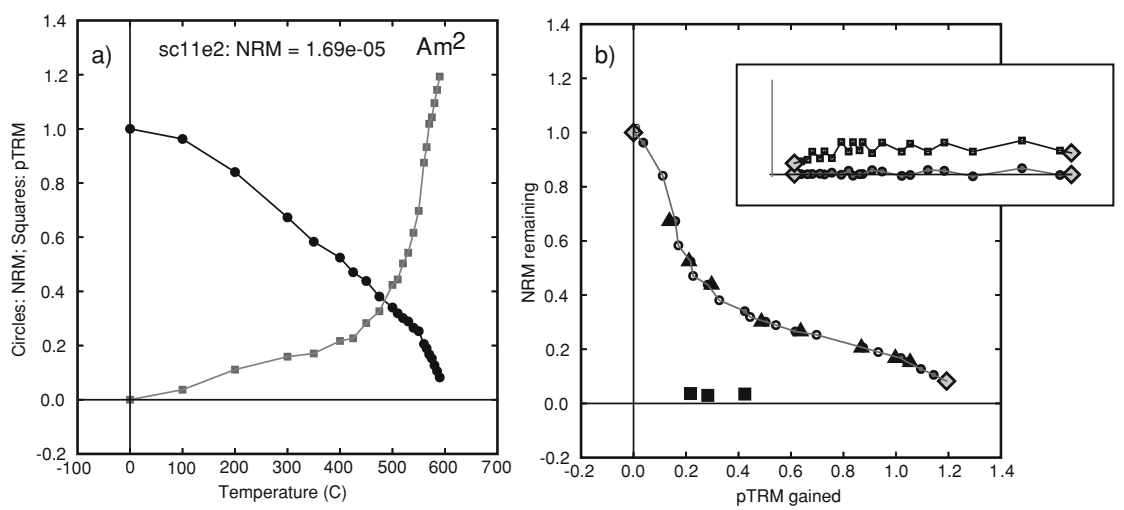

Fig. 8. Representative non-ideal specimen behavior: II. See caption to Fig. 7. Type II specimens are rejected on the grounds that they undergo alteration during the IZZI experiement and because of their behavior during the second Thellier-type experiment.
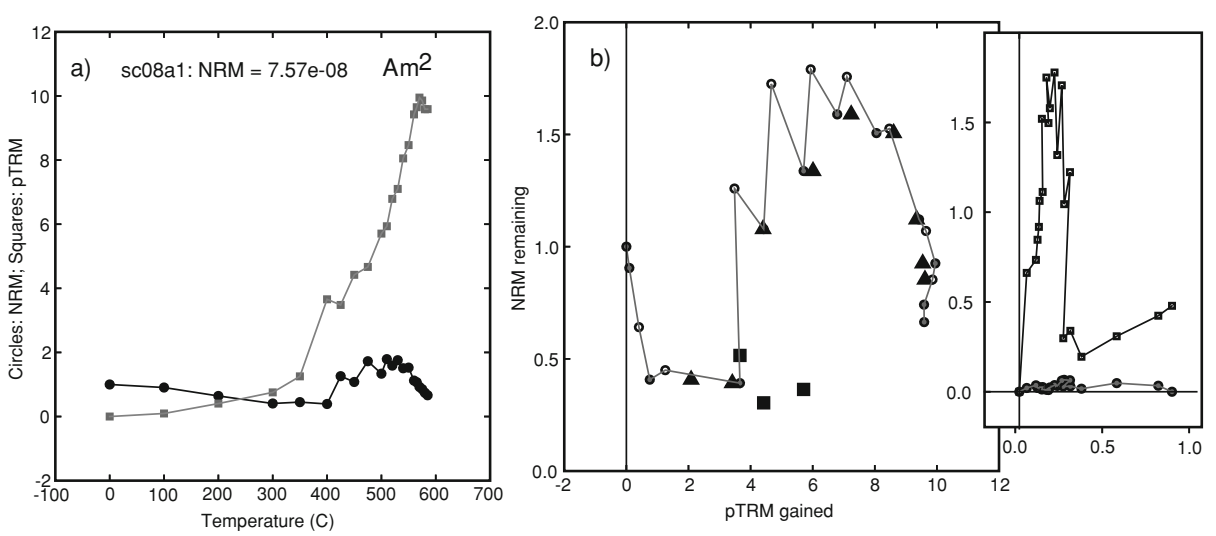

Fig. 9. Representative non-ideal specimen behavior: III. See caption to Fig. 7.
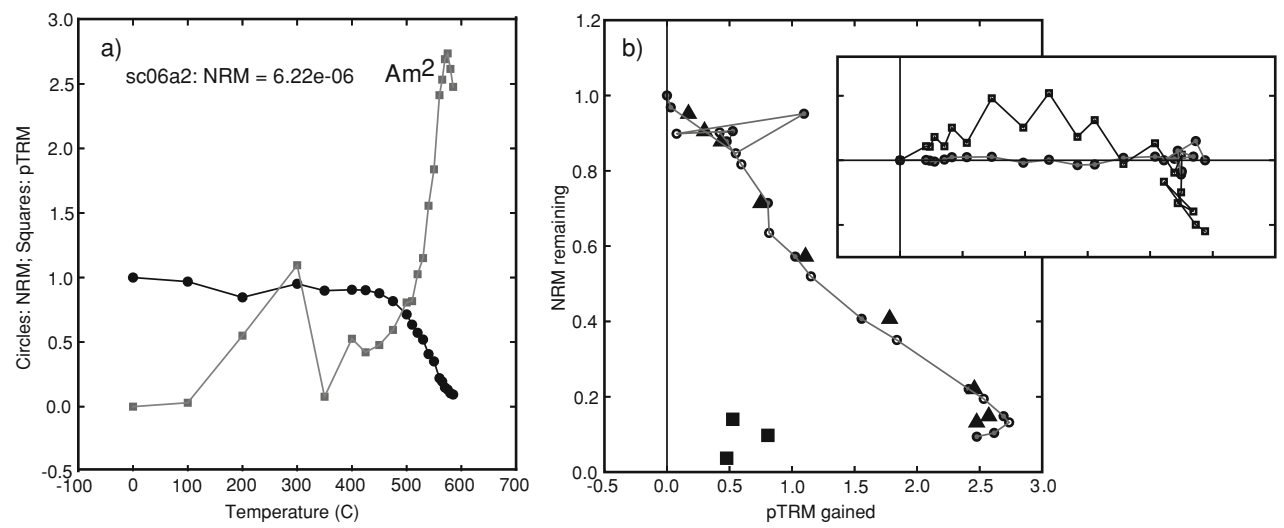

Fig. 10. Results of the second IZZI paleointensity experiment on Type II specimens: See Fig. 9 for comparison. Thermal demagnetization and remagnetization curves and Arai plot after demagnetization of the laboratory TRM (given at $25 \mu \mathrm{T}$ ). The recovered field is the same as the laboratory field.

\subsection{Second Thellier-type experiment applied to Type II} specimens

Often, the curved behavior in the Arai diagrams of Type II behavior can be attributed to a population of multidomain magnetic carriers in the rock (see, e.g., Dunlop and Ozdemir, 1997). Several studies have suggested that a paleointensity estimate can be valid despite marked curvature of Arai plots by using the total TRM (Dunlop and Xu, 1994; Xu and Danlop, 1994; Dunlop and Ozdemir, 1997). However, Dunlop and Ozdemir (1997) caution that there are many possible causes of non-linearity in Arai plots, such as alteration, or multi-component NRMs (for instance, by reheating or overprinting with viscous remanence). Therefore, the cause of the curvature must be well understood before using total TRM to estimate paleointensity.

To investigate the origin of the concave upward behavior in our Type II specimens, we conducted a second thermal paleointensity experiment. Specifically, we designed a test of whether this curved behavior could be caused by alteration rather than the presence of MD grains, despite posti- 
tive pTRM checks.

Selected Type II specimens from sites sc03, sc11, sc19 and sc 23 were given a laboratory TRM cooling from $610^{\circ} \mathrm{C}$ in a $25 \mu \mathrm{T}$ field. The field was applied along the $-X$ direction (specimen coordinates). In the example shown in Fig. 10, the original NRM was nearly parallel to the $-X$ direction and the lab field was approximately orthogonal (parallel to $-Z$ ). In the second experiment, these conditions were therefore reproduced and if the cause of the "sag" is MD behavior, it should be reproducible under these experimental conditions. We carried out a second paleointensity experiment (using the IZ sequence, including pTRM checks to test for alteration). If the curved slopes in the Arai plot are reproducible and the correct intensity can be recovered from the slope connecting the initial and final steps, then we could justify using the total TRM method for calculating paleointensity on the original IZZI data. Conversely, if the experiment were to result in a graph different than the original curved shape, the specimens must be rejected on the grounds that they had changed their ability to acquire a magnetic remanence during the original IZZI experiment, despite the fact that they passed all pTRM check tests.

In the original IZZI experiment, the Type II specimens exhibited a mild Type III behavior in the Zijderveld diagram (zig-zagging toward the laboratory field). That is, the "IZ" set of steps plotted closer to the laboratory field than the "ZI" set of steps. In the second paleointensity experiment we used only the IZ steps in order to detect incipient alteration (on occasion, it is possible to grow a mineral phase in the zero-field first in-field set of steps that is undetectable in the subsequent heating steps).

Results shown in Fig. 10 reveal a magnetic behavior which differs dramatically from the original experiment; we were unable to reproduce the curved shape of the Arai plot, despite the similarity in geometry of the original and second experiments. Therefore, we interpret the curved Arai plots as the result of alteration of the magnetic phases which occurred during the first paleointensity experiment. The alteration product of the first experiment behaves ideally and is an excellent recorder of field applied during the second experiment to within $5 \mu \mathrm{T}$ in all cases, and to within $2 \mu \mathrm{T}$ in most cases. We therefore must reject the Type II specimens from further paleointensity interpretation on the grounds that they alter. However, the directional data obtained during the zero field steps are valid.

\subsection{Site paleointensities and selection criteria}

In order to interpret the paleointensity results from the IZZI experiments, we first selected bounds for paleointensity calculations, handpicking the temperature steps between which:

- The Zijderveld diagram is linear and points toward the origin.

- The Arai plot is linear and the specimen passes pTRM checks.

- The demagnetization curve excludes the 'hump' in demagnetization data (where applicable).

We calculate the best-fit slope between the two temperature steps, and calculate a number of quality control parameters in order to characterize how well each specimen fol- lows the fundamental assumptions of the Thellier-Thellier and Thellier-type paleointensity experiments. These parameters are meant to diagnose noise, mineral alteration and multi-domain behavior.

Below is a short summary of each of the parameters we calculate. For further explanation, please refer to Tauxe and Yamazaki (2007).

- $f_{\mathrm{vds}}$ is the fraction of the total remanence used in the slope calculation (Tauxe et al., 2004). This is distinguished from the $f$ of Coe et al. (1978) because it is the fraction of the total remanence estimated by the vector difference sum.

- MAD, or Maximum Anglular Deviation, measures the scatter about the best-fit line through the zero-field steps used in the paleointensity calculation, and is calculated as in Kirschvink (1980).

- DANG, or Deviation ANGle, characterizes how well the demagnetization data trend toward the origin (Tauxe et al., 2004).

- $\boldsymbol{\beta}$, the scatter parameter, is the standard error of the slope $\sigma$ over the absolute value of the best fit slope $|b|$ (Selkin and Tauxe, 2000).

- The DRATS, or Difference RATio Sum parameter, reflects how well the pTRM checks reproduce the original pTRM acquired at a given temperature step. It is the sum of the difference between these two remanences, normalized by the length of the best-fit slope through NRM/pTRM data (Tauxe et al., 2004).

- The Maximum Difference percent, or MD\%, is the absolute value of the difference of the NRM measured at a given temperature step and the remanence remaining after the pTRM tail check. This value is normalized by the vector difference sum of the NRM and is expressed as a percentage. This measures the amount of pTRM acquired in the laboratory that is not erased by the second zero-field step. The MD\% is meant to flag inequivalency between blocking temperature $\left(T_{\mathrm{b}}\right)$ and unblocking temperature $\left(T_{\mathrm{ub}}\right)$, and to act indirectly as a proxy for multidomain grains (Tauxe et al., 2004).

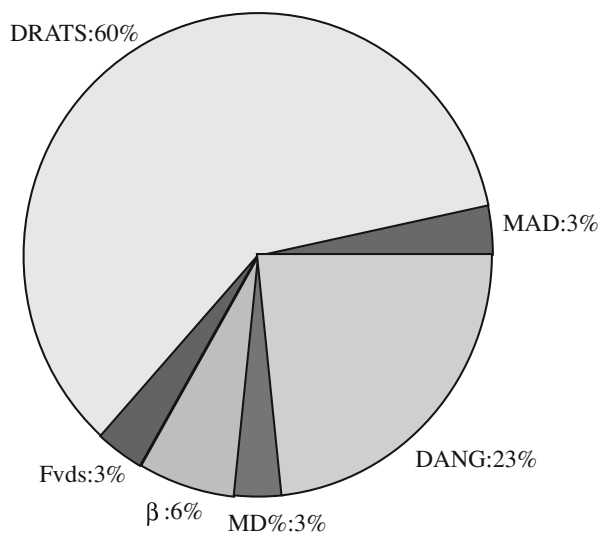

Fig. 11. Selection criterion responsible for failure of grade B specimens: Grade B specimens are those that failed just one of our criteria. The DRATS criterion fails $60 \%$ of specimens, owing to alteration during heating. 
Table 1. Specimen selection criteria for paleointensity. See Section 4.5, Site Paleointensities and Paleointensity Selection Criteria, for parameter definitions.

\begin{tabular}{ccccccccc}
\hline$\sigma \%$ & DRATS & MD $\%$ & $Z$ & $\beta$ & $f_{\text {vds }}$ & MAD & DANG & $N_{\text {samps }}$ \\
\hline 15.0 & 10.0 & 4.0 & 4.0 & 0.09 & 0.3 & 7.0 & 5.0 & 12 \\
20.0 & 10.0 & 4.0 & 4.0 & 0.09 & 0.3 & 7.0 & 5.0 & 12 \\
\hline
\end{tabular}

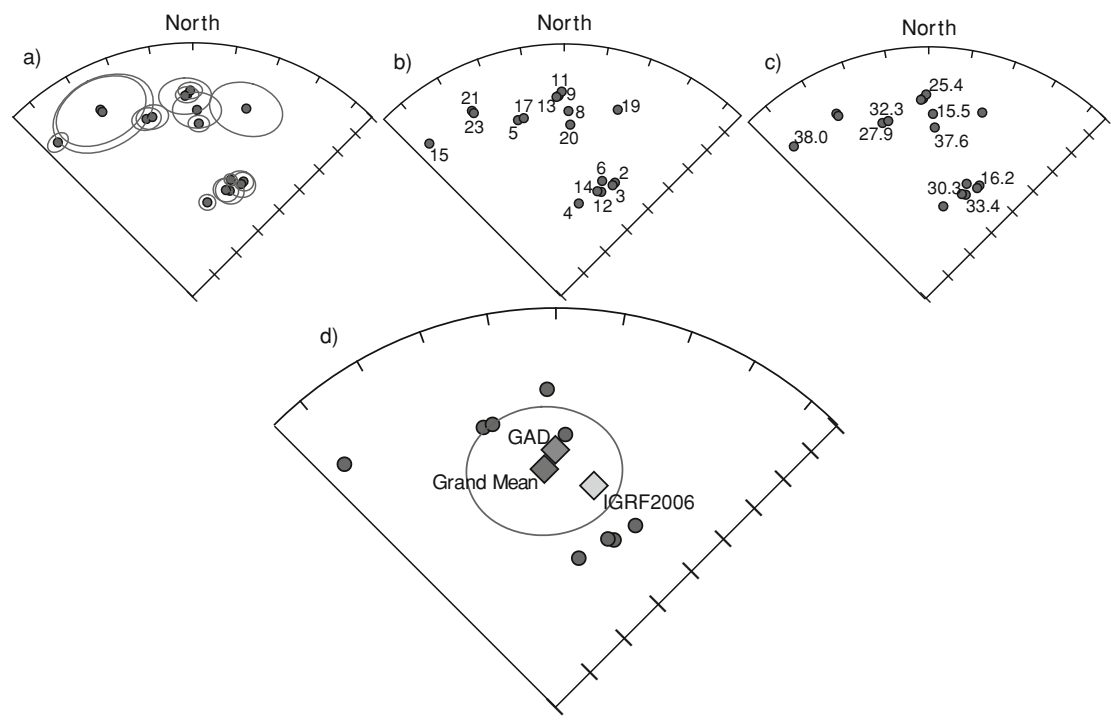

Fig. 12. Directional data: (a) Equal area plot of site mean paleomagnetic directions with $\alpha_{95}$ confidence circles. (b) Same plot as (a) but with site numbers included next to their corresponding direction. (c) Same plot as (a) and (b), but with estimated paleointensities included next to their corresponding direction. (d) An equal area plot showing the grand mean direction for all sites, the direction expected from that of a geocentric axial dipole (GAD) and the current International Geomagnetic Reference Field (IGRF) direction at Isla Socorro.

Summary statistics from all our specimens as well as all the original measurements are available in the MagIC database. Having interpreted each result as consistently as possible, we must somehow decide which data are "reliable" and which are not. Most studies set critical values for the paleointensity parameters, and these are normally chosen in a rather arbitrary manner. Ben Yosef et al. (2008) argue that the most convincing element of any scientific study is reproducibility and within-site consistency. Therefore, in an attempt to reduce the subjectivity of assigning selection critera, they find the strictest set of criteria that optimizes the degree of within-site consistency between paleointensity values $\left(B_{\text {anc }}\right)$ from the same site.

Following the optimization approach of Ben Yosef et al. (2008) and choosing to accept sites with a standard deviation of $15 \%$ of the mean value or less than $5 \mu \mathrm{T}$, the critical values listed in Table 1 yielded the most acceptable sites. Specimens are given a letter grade based on how many criteria they fail. Those that pass all criteria are given a grade of "A", those that fail one criterion are given a grade of "B", etc. Only specimens that meet all of our criteria (grade "A" specimens) are used in the calculation of site paleointensities.

Of the 90 specimens that underwent the IZZI protocol, 21 met all of our selection criteria, yielding 9 acceptable site mean paleointensity values for a success rate of $52 \%$. In addition, a further 50 unoriented specimens (from the original Bohrson et al. (1996) study) yielded eight acceptable specimens, bringing in three additional acceptable sites.
Of the sites that failed a single acceptance criterion (grade "B" specimens), the majority were eliminated by the DRATS criterion (see Fig. 11). Because DRATS measures whether a specimen's ability to acquire a remanence at a given temperature step changes throughout the heating experiment, we conclude that the majority of specimens undergo alteration during heating and must be rejected.

It is comforting that specimens demonstrating the categorical magnetic misbehaviors (II-IV) are eliminated by our chosen selection criteria. Site mean intensities for those specimens that passed our criteria are given in Table 2 .

\subsection{Site directions and directional criteria}

Directions obtained from the zero field steps of the IZZI experiment and the AF demagnetization data are plotted in Fig. 12(a)-(c). We accept specimens with a MAD < 10. Of the 108 specimens demagnetized either by AF or in the zero-field steps of the IZZI experiments, 77 gave acceptable directions. Site mean directions and their corresponding confidence circles $\left(\alpha_{95}\right.$ (Fisher, 1953)) are shown in Fig. 12(a) and are listed in Table 2.

Based on proximity in the field, we suspected that several sites may have in fact sampled the same lava flow. To test for this, we posit that the same lava flow must have the same direction and paleointensity (when available). When two sites have no overlap in their $\alpha_{95}$ confidence circles, we interpret those sites as having distinct directions. However, there are some ambiguities when the $\alpha_{95} \mathrm{~s}$ of two sites overlap (see for example, sites sc19 and sc08, or sc08 and sc20). When a site's $\alpha_{95}$ includes the mean of another site 
Table 2. Summary of paleomagnetic results. Age and Age $\sigma$ and group (age group) are taken from Bohrson et al. (1996). $N_{\text {int }}$ is the number of samples included in the site paleointensity calculation. $B_{\text {anc }}$ and $B_{\text {anc }} \sigma$ is the calculated ancient magnetic field and the standard error. $N_{\text {dir }}$ is the number of samples used in the site mean direction calculations. $\bar{D}$ and $\bar{I}$ are the site mean declinations and inclinations, respectively. $\alpha_{95}$ is the $95 \%$ cone of confidence. See text for defined magnetic behaviors.

\begin{tabular}{|c|c|c|c|c|c|c|c|c|c|c|c|c|c|c|}
\hline Site & Latitude & Longitude & Age & Age $\sigma$ & Group & $N_{\text {int }}$ & $B_{\text {anc }}$ & $B_{\text {anc }} \sigma$ & $N_{\text {dir }}$ & $\bar{D}$ & $\bar{I}$ & $\kappa$ & $\alpha_{95}$ & Behavior \\
\hline sc01 & 18.73005 & -110.95121 & & & & & & & & & & & & \\
\hline $\mathrm{sc} 02$ & 18.78167 & -110.92367 & & & & 2 & 16.2 & 2.3 & 8 & 22.1 & 48.9 & 458.5 & 2.6 & I \\
\hline $\mathrm{sc} 03$ & 18.7793 & -110.9206 & & & & & & & & & & & & II, IV \\
\hline sc04 & 18.78116 & -110.92203 & & & & & & & 5 & 8.8 & 59.2 & 856.8 & 2.6 & \\
\hline sc05 & 18.775 & -110.917 & & & & 2 & 27.9 & 1.5 & 5 & 346.5 & 28.0 & 137.8 & 6.7 & I \\
\hline sc06 & 18.77686 & -110.91888 & & & & & & & & & & & & III, IV \\
\hline sc08 & 18.78503 & -110.95902 & & & & 3 & 15.5 & 2.3 & & & & & & III \\
\hline sc09 & 18.77505 & -110.95794 & & & & 2 & 25.4 & 0.5 & 6 & 357.6 & 21.2 & 374.6 & 3.5 & III \\
\hline sc11 & 18.7885 & -110.92905 & & & & & & & & & & & & I \\
\hline $\mathrm{sc} 12$ & 18.7748 & -110.91856 & & & & 4 & 33.4 & 4.1 & 8 & 19.5 & 54.3 & 137.9 & 4.7 & II, III \\
\hline sc13 & 18.78852 & -110.92905 & & & & & & & & & & & & \\
\hline sc14 & 18.77789 & -110.92008 & & & & 2 & 30.3 & 1.1 & 8 & 17.3 & 53.8 & 199.8 & 3.9 & \\
\hline sc15 & 18.7934 & -110.92596 & & & & 2 & 38.0 & 0.1 & 5 & 317.9 & 20.8 & 862.3 & 2.7 & \\
\hline sc16 & 18.77648 & -110.91876 & & & & & & & & & & & & \\
\hline sc17 & 18.8016 & -110.9193 & & & & 2 & 32.3 & 1.0 & 6 & 347.3 & 28.3 & 225.4 & 4.5 & \\
\hline sc 18 & 18.78337 & -110.91602 & & & & & & & & & & & & \\
\hline sc19 & 18.75232 & -110.92082 & & & & & & & & & & & & II, III \\
\hline $\operatorname{sc} 20$ & 18.74581 & -110.95458 & & & & 2 & 37.6 & 0.1 & 5 & 2.1 & 32.2 & 422.1 & 3.7 & III \\
\hline sc21 & 18.78512 & -110.91971 & & & & & & & & & & & & II, III \\
\hline $\mathrm{sc} 23$ & 18.7833 & -110.91677 & & & & & & & & & & & & II, III \\
\hline $90-53$ & 18.783 & -110.916 & 534 & 6 & A & & & & & & & & & III \\
\hline $91-46$ & 18.762 & -110.917 & 518 & 5 & A & & & & & & & & & \\
\hline $90-13$ & 18.786 & -110.918 & 523 & 5 & A & & & & & & & & & II \\
\hline $90-43 B$ & 18.798 & -110.923 & 481 & 5 & $\mathrm{C}$ & 4 & 27.5 & 2.7 & & & & & & \\
\hline $90-90$ & 18.755 & -110.965 & 434 & 5 & D & & & & & & & & & IV \\
\hline $91-52$ & 18.744 & -110.956 & 430 & 4 & D & 2 & 26.0 & 1.9 & & & & & & \\
\hline $91-23$ & 18.755 & -110.954 & 372 & 4 & E & & & & & & & & & IV \\
\hline $90-36$ & 18.780 & -110.921 & 372 & 4 & E & & & & & & & & & IV \\
\hline 91-32 & 18.756 & -110.918 & 368 & 4 & $\mathrm{E}$ & 2 & 25.8 & 0.7 & & & & & & \\
\hline Grand mean & & & & & & 12 & 30.0 & 7.1 & 9 & 357.2 & 40.2 & 13.6 & 14.5 & \\
\hline
\end{tabular}




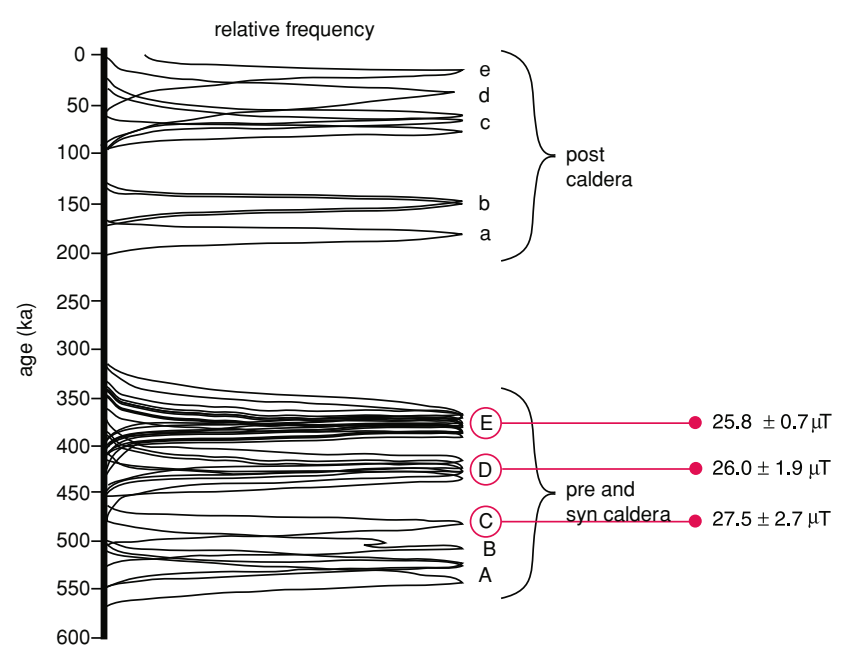

Fig. 13. Argon-argon ages and paleointensities: Same as Fig. 2, but included also are paleointensity estimates from tests conducted on the dated samples.

(e.g. sc08 and sc20), we interpret the two site directions as indistinct from one another. On the other hand, when two $\alpha_{95}$ confidence circles overlap, but do not include the mean of the other site (e.g. sc19 and sc08) the interpretation is more ambiguous. In these cases, we use Watson's F test (see Tauxe (1998) for details).

\section{Discussion}

\subsection{Correlations}

Paleointensity values are enhanced in value if they have correspondingly reliable ages. We attempt to use what we know from the previous study to attach ages to the samples from the present study.

All of the sites from Bohrson et al. (1996) have associated ages, site descriptions, lithological information and site locations (however as the study was carried out before GPS was widely used, site locations are only known to within $0.5 \mathrm{~km}$ ). In a preliminary paleointensity experiment administered to unoriented specimens from that study, three sites meet our acceptance criteria, and consequently have ages. In addition to paleointensity information, we also characterized the magnetic behavior of these specimens during the heating experiment (a standard ZI only paleointsity experiment) and assigned them to Type I, Type II, Type III and Type IV categories along with the results collected for the present study (Table 2).

We attempted to correlate the sites of this study to those of Bohrson et al. (1996) based on the following characters: site location, site description and lithology, site paleointensities and remanent intensities, and specimen magnetic behaviors. However, correlation proved very difficult and we are unable to make any unambiguous ties between the ages/sites of the old data set and the new.

Our attempts to correlate between the two studies suffer from several drawbacks:

1) We cannot use location alone to correlate between sites:

- Sites sc20 and 91-52 are quite close to one an-

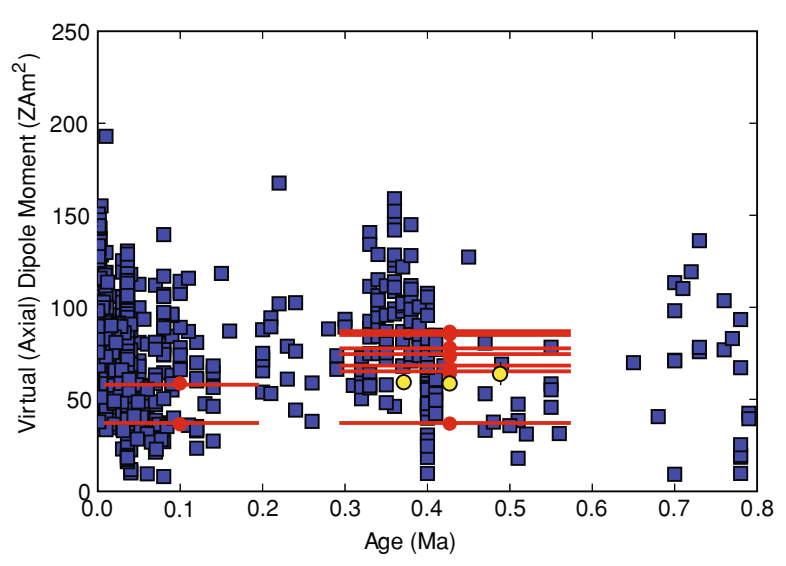

Fig. 14. Virtual (Axial) Dipole Moment over the Bruhnes Chron: V (A)DM plotted versus time in millions of years. Blue squares are VDM values from the PINT06 database. Open yellow circles are VADMs for Socorran sites with well-constrained ages. Red circles are VADMs for Socorran sites with known age ranges.

other, but yield markedly different paleointensities and are therefore interpreted as two different cooling units.

2) We cannot use intensity alone to correlate between sites:

- Sites 91-32, 91-52 and 90-43B have distinct ages but share paleointensities within error.

3) We cannot use direction alone to correlate between sites:

- Sites sc05 and sc17 have the same site directions but have markedly different site paleointensities.

4) Some age units (e.g. age unit E) apparently span a sufficient length of time to include significant secular variation:

- Sites sc02 and sc04 must both be unit E based on stratigraphy (they fall between two sites dated as age group E), but their directions are distinct.

Nonetheless, we are confident that we oversampled at least two units:

- Sites sc12 and sc14 have the same directions based on Watson's F test (Tauxe, 1998), the same intensity values, and were sampled from nearby outcrops and are therefore interpreted as being the same unit.

- Sites sc11 and sc13 have the same directions (although their directions are not included in the mean calculation because their $k$ values are less than 100) and are located very close to one another, and are therefore interpreted as the same unit.

We are unable to make any solid correlations between the age and paleointensity data sets, but are able to diagnose redundancy in our own sampling. Nonetheless, we have three certain paleointensity estimates from the unoriented samples of Bohrson et al. (1996) that we plot alongside their argon-argon dates in Fig. 13. These three intensities 
Table 3. Virtual axial dipole moments and virtual geomagnetic poles for Socorro. $N_{\text {vadm }}$ is the number of data points included in VADM calculations. VADM and $\sigma_{\text {vadm }}$ are the virtual axial dipole moment and the uncertainty, both in ZAm ${ }^{2} . N_{\text {vgp }}$ is the number of data points included in calculation of VGP latitude and longitude Lat ${ }_{\mathrm{vgp}}$, and $\mathrm{Lon}_{\mathrm{vgp}}$, respectively. $\delta p$ and and $\delta m$ are the latitudinal uncertainty and longitudinal uncertainty in VGP, respectively.

\begin{tabular}{|c|c|c|c|c|c|c|c|c|}
\hline Site & $N_{\text {vadm }}$ & VADM & $\sigma_{\text {vadm }}$ & $N_{\text {vgp }}$ & $\mathrm{Lat}_{\mathrm{vgp}}$ & Lon $_{\text {vgp }}$ & $\delta p$ & $\delta m$ \\
\hline $90-43 B$ & 4 & 62.0 & 6.03 & & & & & \\
\hline $91-32$ & 2 & 58.1 & 1.64 & & & & & \\
\hline $91-52$ & 2 & 58.7 & 4.32 & & & & & \\
\hline $\mathrm{sc} 02$ & 2 & 36.6 & 5.21 & 9 & 65.7 & 307.3 & 2 & 4.5 \\
\hline $\mathrm{sc0} 04$ & & & & 5 & 67.5 & 266.9 & 1.7 & 4.8 \\
\hline $\mathrm{sc} 05$ & 2 & 62.9 & 3.46 & 8 & 75.6 & 146.9 & 2.7 & 4.4 \\
\hline $\operatorname{sc} 08$ & 3 & 35.0 & 5.27 & & & & & \\
\hline sc09 & 2 & 57.2 & 1.10 & 9 & 82.2 & 80.7 & 2 & 3.2 \\
\hline sc12 & 4 & 75.3 & 9.15 & 9 & 67 & 293.4 & 2.9 & 7 \\
\hline sc14 & 2 & 68.3 & 2.47 & 8 & 68.1 & 290.3 & 2.6 & 6.3 \\
\hline sc 15 & 2 & 85.7 & 0.21 & 6 & 49.4 & 153.3 & 2 & 3.1 \\
\hline $\mathrm{sc} 17$ & 2 & 72.8 & 2.20 & 6 & 77.3 & 143.9 & 3 & 4.8 \\
\hline sc20 & 2 & 84.8 & 0.26 & 7 & 87.7 & 11.1 & 2 & 3.4 \\
\hline
\end{tabular}

are from age groups 'C,' 'D,' and 'E,' and fall within error of one another. We plan next to date the sites from this study from which we obtained reliable paleointensity estimates.

\subsection{Average field strength}

From the equator to the poles, the geomagnetic field intensity varies approximately by a factor of two; hence in order to compare paleointensity values over the globe, we convert intensity to a virtual axial dipole moment (VADM). A VADM is the corresponding moment of a geocentric dipole aligned with the spin axis that would produce the observed intensity at a given latitude. We report individual site VADMs in Table 3. The average intensity value we recover for Socorro is $30 \pm 7.1 \mu \mathrm{T}$, corresponding to an average VADM of $67.6 \pm 16.0 \mathrm{ZAm}^{2}$. This is a low value when compared to the present field, which has a dipole moment of about $89 \mathrm{ZAm}^{2}$ (IGRF 1995 at Socorro), and is also lower than the often quoted averages over last five million yearsalso about $80 \mathrm{ZAm}^{2}$ (e.g. Mcfadden and McElhinny, 1982), but higher than that estimated by Selkin and Tauxe (2000) ( $\sim 57 \mathrm{ZAm}^{2}$ for the period 0.3-300 Ma).

In lieu of using VADM, many studies report virtual dipole moment (VDM) which uses magnetic co-latitude in place of site co-latitude and a recent compilation of all absolute and sedimentary paleointensities, Tauxe and Yamazaki (2007) demonstrated a 1-to-1 correspondence between VDM and VADM. We plot the VADM data from this study with V[A]DM data from the PINT06 data set (Tauxe and Yamazaki, 2007) in Fig. 14. The three values with associated ages are plotted in yellow. The values with estimated age ranges are plotted in red. Dating the nine high quality paleointensity estimates presented here would add greatly to the discussion of average field strength during the Brunhes.

\subsection{Directional variability}

Mean site directions for the present study are summarized in Table 2, and plotted in Fig. 12. Often, in order to compare directions over a range of latitudes, paleomagnetic directions are not reported as a set of declinations and inclinations, but rather as virtual geomagnetic poles (VGPs; the point on the globe that corresponds to the axis of a geocentric dipole that would produce the observed direction at the site location). These are listed in Table 3.

Paleosecular variation (PSV) is the temporal variation of the geomagnetic field over various spatial scales. The geocentric axial dipole hypothesis (GAD) predicts that the direction of the geomagnetic field, averaged over time, is approximately that of a bar magnet aligned with the spin axis. However, the geomagnetic field may have significant deviations from GAD from long-lived non-dipolar contributions (see e.g., Lawrence et al., 2006; Johnson and McFadden, 2007). One popular way to summarize the degree of secular variation over time is the use of the angular dispersion, or scatter parameter, $S$ (Cox, 1969). The $S$ value for Socorro is $23_{30}^{15}$. (Results are the same for VGP cutoff of $45^{\circ}$ and the variable cutoff of Vandamme (1994).) This dispersion is consistent with the dispersion for Mexico recognized by Lawrence et al. (2006), $21.1 \pm 4.4^{\circ}$, and much higher than that predicted by the most frequently cited PSV model, Model G (McElhinny et al., 1996). The Mexican value of $S$ is also higher than that of Hawaiian directions, which is $16.4 \pm 1.3^{\circ}$ quoted by Lawrence et al. (2006). Nonetheless, the mean direction for Soccoro is consistent with that predicted by the dipole formula. Figure 12(d) shows the grand mean of the directional data plots very close to the GAD field.

\subsection{Ignimbrites?}

Ignimbrites are volcanic, usually rhyolitic in composition, and consist of fine-grained igneous fragments including ash, glass and lithics. They are the result of gravitydriven flows, and are formed when an eruptive column collapses. Ignimbrites can be distinguished from other pyroclastic deposits because they are emplaced at very high temperatures and often undergo an amount of welding or sintering together of grains as they cool under their own weight. The anatomy of a 'typical' ignimbrite deposit includes a ground surge deposit at the base, a fine-grained (reverse graded) basal layer, the 'body,' which comprises $98 \%$ of the ignimbrite package and can display various grades of welding, and finally, a fine ash deposit on top. Often, only the body of the ignimbrite is preserved (Sparks and Wallker, 1973).

Peralkaline-silicic ignimbrites are further distinguishable 


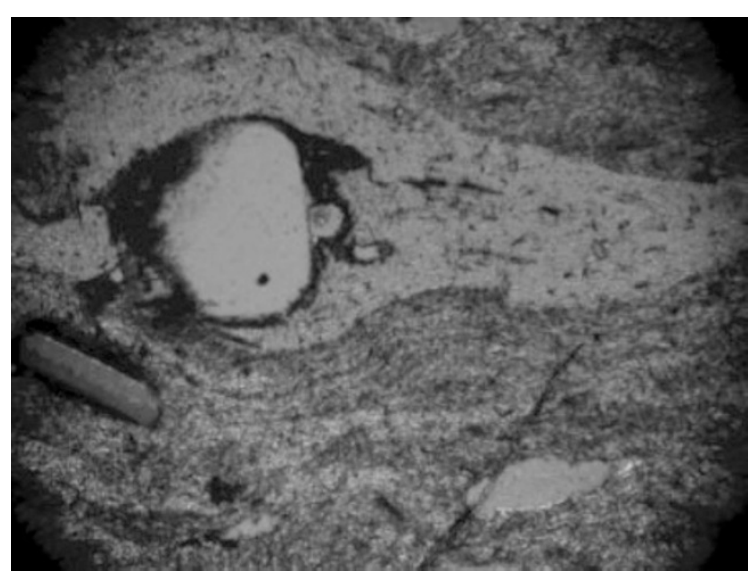

Fig. 15. Photomicrograph demonstrating ignimbritic texture-site sc09: Site sc09 reveals flattened pumice (fiamme) and textural banding, characteristic of an ignimbrite (40X).

(from calc-alkaline ignimbrites) by their low viscosity, their high emplacement temperatures, particularly dense flows, rapid welding, and relatively small volumes. They are commonly associated with caldera collapse (Schmincke, 1974), so it is not unexpected that the pre- and in particular the syn-caldera rocks would include ignimbrite deposits.

However, evidence for welding includes: flattened pumice (fiamme) or lithic fragments set in an ashy matrix, often with a eutaxitic texture (foliations or streaked appearances due to the alternation of lenses of different textures and compositions). We found no evidence of diagnostic ignimbritic textures in the thin sections from the pre- and syncaldera samples (see Fig. 3). This was partially expected, in the case of pumice and lithics, as we avoided sampling the lithic sections of Bohrson et al. (1996), and instead targeted the hard, coherent, massive units which we thought would be more useful for obtaining a paleointensity. Bohrson et al. (1996) found the dense sections lacking in fiamme inclusions and lithics, which they say are preserved only on local horizons. However, in our thin sections, we see no evidence for welding either (no eutaxitic foliation).

Bohrson et al. (1996) suggest, that the pre- and syncaldera units sampled are rheomorphic tuffs, which are often mistaken for silicic lavas and vice versa (Henry and Wolff, 1992). We are cautious in identifying the pre- and syn-caldera rocks as ignimbrites, although we acknowledge other pyroclastic features in the stratigraphy (pumice, lithics, etc.). We prefer to think of them as lava flows interbedded with surge and ash deposits.

One post-caldera unit that we sampled in the caldera floor (sc09, Cerro Evermann Fm), which was mapped as a rhyolitic flow, is the one unit that we are confident is highly welded and ignimbritic in nature (Quane and Russell, 2005). The thin section in Fig. 15 clearly demonstrates the fabric of an ignimbrite, shown in the figure is a lensshaped pumice fragment and compositional banding.

\section{Conclusions}

- Although many specimens altered during the IZZI experiment, 21 of 90 specimens passed strict selection criteria, yielding acceptable paleointensity esti- mates from 9 sites. A further 50 specimens subjected to a simple Coe-modified Thellier experiment passed the same acceptance criteria and yielded 8 acceptable paleointensity estimates from 3 additional sample sites. The mean of all acceptable site intensities is $30.0 \pm 7.1 \mu \mathrm{T}$ equivalent to a VADM of $67.6 \pm 16.0 \mathrm{ZAm}^{2}$.

- We find little evidence that the units mapped as ignimbrites were welded, and instead interpret them as lava flows.

- However, we find that these silicic peralkaline lava flows can be suitable for paleointensity studies.

- The average direction is $D=357.2, I=40.2$, consistent with the geocentric axial dipole direction at Socorro.

- The VGP scatter, $23_{30}^{15}$ is higher than previous estimates (e.g. model $\mathrm{G}$ of McElhinny, McFadden and Merrill), but consistent with that of Lawrence et al. (2006) for Hawaii and Mexico and Johnson and McFadden (2007).

- We are unable to unambiguously tie the ages of Bohrson et al. (1996) to our 2006 sample collection.

Acknowledgments. We thank the Mexican Navy for transporting us to Isla Socorro quickly and safely, and for their generous field support and hospitality. We gratefully acknowledge the members of the combined class in paleomagnetism for their assistance in the field: Peter Baker, Jorge Castro, Ligia Perez Cruz, Kristin Lawrence, Jason Steindorf, and Leah Ziegler. We also thank Hubert Staudigel and Jeff Gee for their input and discussions. Andy Biggen and anonymous provided thoughtful reviews which improved the manuscript. This work was made possible through UCMEXUS-CONACYT grant number 20042963 and was supported by NSF grants 0229403 and 0636051 . AG is gratefful for financial support given by DGAPA IN102007.

\section{References}

Aitken, M. J., A. L. Allsop, G. D. Bussell, and M. B. Winter, Determination of the intensity of the earth's magnetic field during archeological times: reliability of the thellier technique, Rev. Geophys., 26, 3-12, 1988.

Batiza, R. and D. A. Vanko, Petrologic evolution of large failed rifts in the eastern pacific: Petrology of volcanic and plutonic rocks from the mathematician ridge area and the guadalupe trough, J. Petrol., 26(3), 564-602, 1985.

Ben Yosef, E., H. Ron, L. Tauxe, A. Agnon, A. Genevey, T. Levy, U. Avner, and M. Najjar, Application of copper slag in geomagnetic archaeointensity research, J. Geophys. Res., 2008 (in press).

Bohrson, W. A. and M. R. Reid, Genesis of silicic peralkaline volcanic rocks in an ocean island setting by crustal melting and open-system processes: Socorro island, mexico, J. Petrol., 38(9), 1137-1166, 1997.

Bohrson, W. A., M. R. Reid, A. L. Grunder, M. T. Heizler, T. M. Harrison, and J. Lee, Prolonged history of silicic peralkaline volcanism in the eastern pacific ocean, J. Geophys. Res., 101(B5), 11,457-11,474, 1996.

Bryan, W. B. J., High-silica alkaline lavas of Clarion and Socorro Islands, Mexico - their genesis and regional significance, $\mathrm{PhD}$ thesis, University of Wisconsin, 1960.

Coe, R. S., The determination of paleo-intensities of the earth's magnetic field with emphasis on mechanisms which could cause non-ideal behavior in the thellier's method, J. Geomag. Geoelectr., 19, 157-178, 1967.

Coe, R. S., S. Gromme, and E. A. Mankinen, Geomagnetic paleointensities from radiocarbon-dated lavaflows on hawaii and the question of the pacific nondipole low, J. Geophys. Res., 83, 1740-1756, 1978.

Cox, A., Confidence limits for the precision parameter k, Geophys. J. Roy. Astron. Soc., 17, 545-579, 1969.

Doell, R. R. and A. Cox, The pacific geomagnetic secular vatiation anomaly and the question of lateral uniformity in the lower mantle, in The Nature of the Solid Earth, edited by E. C. Robertson, 245-284, McGraw-Hill, New York, NY, 1972. 
Dunlop, D. J. and S. Xu, Theory of partial thermoremanent magnetization in multidomain grains 1 . repeated identical barriers to wall motion (single microcoercivity), J. Geophys. Res., 99(B5), 9005-9024, 1994.

Dunlop, D. J. and O. Ozdemir, Rock Magnetism: Fundamentals and Frontiers, Cambridge University Press, New York, 1997.

Farmer, J. D., M. C. Farmer, and R. Berger, Radiocarbon ages of lacustrine deposits in volcanic sequences of the lomas coloradas area, socorro island, mexico, Radiocarbon, 35(2), 253-262, 1993.

Fisher, R. A., Dispersion on a sphere, Proc. Roy. Soc. London A, 217, 294 $305,1953$.

Henry, C. D. and J. A. Wolff, Distinguishing strongly rheomorphic tuffs from extensive silicic lavas, Bull. Volcanol., 54, 171-186, 1992.

Johnson, C. L. and P. McFadden, The time-averaged field and paleosecular variation, in Geomagnetism, Treatise on Geophysics, 2007 (in press).

Johnson, C. L., C. G. Constable, and L. Tauxe, Mapping long-term changes in earth's magnetic field, Science, 300, 2044-2045, 2003.

Kirschvink, J. L., The least-squares line and plane and the analysis of paleomagnetic data, Geophys. J. Roy. Astron. Soc, 62(3), 699-718, 1980.

Laj, C., H. Guillou, N. Szeremeta, and R. S. Coe, Geomagnetic paleosecular variation at hawaii around 3 ma from a sequence of 107 lava flows at kaena point (oahu), Earth Planet. Sci. Lett., 170(4), 365-376, 1999.

Lawrence, K. P., C. G. Constable, and C. L. Johnson, Paleosecular variation and the average geomagnetic field at $+/-20$ degrees latitude, Geochem. Geophys. Geosyst. 7(7), 2006.

Mammerickx, J., D. F. Naar, and R. L. Tyce, The mathematician paleoplate, J. Geophys. Res., 93(B4), 3025-3040, 1988.

McElhinny, M. W., P. McFadden, and R. T. Merrill, The time-averaged paleomagnetic field 0-5 ma, J. Geophys. Res., 101(B11), 25,007-25,028, 1996.

McFadden, P. and M. W. McElhinny, Variations in the geomagnetic dipole 2: statistical analysis of vdm's for the past 5 m.y., J. Geomag. Geoelectr., 34, 163-189, 1982.

Quane, S. L. and J. K. Russell, Ranking welding intensity in pyroclastic deposits, Bull. Volcanol., 67, 129-143, 2005.

Richards, A. F., Geology of the islas revillagigedo, mexico, 2. geology and petrography of isla san benedicto, 1966.

Richards, A. F. and B. H. Brattstrom, Bibliography, cartography, discovery, and exploration of the islas revillagigedo, 1959.

Riisager, P. and J. Riisager, Detecting multidomain magnetic grains in thellier palaeointensity experiments, Phys. Earth Planet. Inter., 125, 111-117, 2001.
Schlinger, C. M., D. R. Veblen, and J. G. Rosenbaum, Magnetism and magnetic mineralogy of ash flow tuffs from yucca mountain, nevada, $J$. Geophys. Res., 96(B4), 6035-6052, 1991.

Schmincke, H.-U., Volcanological aspects of peralkaline silicic welded ash-Mflow tuffs, Bull. Volcanol., 38(2), 594-636, 1974.

Selkin, P. A. and L. Tauxe, Long-term variations in palaeointensity, Roy. Soc., 358, 1065-1088, 2000.

Selkin, P. A., J. S. Gee, and L. Tauxe, Nonlinear thermoremanence acquisition and implications for paleointensity data, Earth Planet. Sci. Lett., 256, 81-89, 2007.

Siebe, C., J.-C. Komorowski, C. Navarro, J. McHone, H. Delgado, H., and A. Cortes, Submarine eruption near socorro island, mexico: Geochemistry and scanning electron microscopy studies of floating scoria and reticulite, J. Volcanol. Geotherm. Res., 68, 239-271, 1995.

Sparks, R. S. J. and G. P. L. Walker, Products of ignimbrite eruptions, Geology, 115-118, 1973.

Taran, Y. A., T. P. Fischer, E. Cienfuegos, and P. Morales, Geochemistry of hydrothermal fluids from an intraplate ocean island: Everman volcano, socorro island, mexico, Chem. Geol., 188(1-2), 51-63, 2002.

Tauxe, L., Paleomagnetic Principles and Practice, Modern Approaches in Geophysics, Kluwer Academic Publishers, Dordrecht, 1998.

Tauxe, L., P. Gans, and E. A. Mankinen, Paleomagnetism and 40ar/39ar ages from volcanics extruded during the matuyama and brunhes chrons near mcmurdo sound, antarctica, Geochem. Geophys. Geosyst., 5(6), 120, 2004.

Tauxe, L. and T. Yamazaki, Paleointensities, in Geomagnetism, 5, 2007 (in press).

Vandamme, D., A new method to determine paleosecular variation, Phys. Earth Planet. Inter., 85, 131-142, 1994.

White, W. M., M. D. M. Tapia, and J.-G. Schilling, The petrology and geochemistry of the azores islands, Contr. Mineral. Petrol., 69(3), 201213, 1979.

$\mathrm{Xu}, \mathrm{S}$. and D. J. Dunlop, Theory of partial thermoremanent magnetization in multidomain grains 2 . effect of microcoercivity distribution and comparison with experiment, J. Geophys. Res., 99(B5), 9025-9034, 1994.

E. Sbarbori, L. Tauxe (e-mail: ltauxe@ucsd.edu), A. Goguitchaichvili, J. Urrutia-Fucugauchi, and W. A. Bohrson 